\title{
PENINGKATAN PENGETAHUAN IBU-IBU RUMAH TANGGA DALAM PERILAKU PENGOBATAN SENDIRI UNTUK PENATALAKSANAAN DEMAM DENGAN IMETODE CARA BELAJAR IBU AKTIF
}

\author{
Increased Knowledge of Housewives in Self-Treatment Behavior for Fever Management Using \\ Active Mother's Ways of Learning Method
}

\author{
Rezqi Handayani \\ Department of Pharmacy, Faculty of Health Science, Universitas Muhammadiyah Palangkaraya, RTA. Milono St. Km. I.5 Palangka Raya, \\ Indonesia \\ *e-mail : rezqi.handayani@gmail.com
}

\begin{abstract}
ABSTRAK
Terapi Farmakologi pada penderita demam adalah dengan memberikan obat golongan Antipireutik, dapat dilakukan dengan menggunakan resep dokter atau dengan swamedikasi. Kondisi yang terjadi di masyarakat adalah swamedikasi yang dilakukan berada dalam kategori terapi pengobatan tidak rasional karena tidak sesuai dengan kondisi penderita terutama dalam dosis obat yang diberikan. Maka perlu dilakukan edukasi dengan menggunakan metode Cara Belajar lbu Aktif kepada ibu rumah tangga mengenai swamedikasi demam yang rasional. Sampel pada penelitian ini adalah ibu rumah tangga di Kawasan Flamboyant Bawah, sebanyak 40 orang dan dibagi dalam dua kelompok besar yaitu kelompok kontrol dan perlakuan. Setiap kelompok diberikan pretest dan postest dalam bentuk kusioner tentang penatalaksanaan demam. Pada kelompok perlakuan sebelum diberikan postest diberikan edukasi obat demam dalam bentuk metode CBIA. Hasil penelitian menunjukkan adanya peningkatan pengetahuan para ibu rumah tangga dari sebelum dilakukan edukasi dan setelah edukasi yang terlihat dari perolehan nilai. Rerata nilai pretest pada kelompok kontrol adalah 74.38 dan kelompok perlakuan sebesar 69.69. Hasil uji statistik menunjukkan tidak ada perbedaan yang signifikan rerata nilai antara kelompok kontrol dan kelompok perlakuan ( $\mathrm{t}$ hitung<t tabel). Rerata nilai postest pada kelompok kontrol adalah 77.8I dan kelompok perlakuan sebesar 87.50. Terdapat perbedaan yang signifikan antara rerata nilai kelompok kontrol dan kelompok perlakuan ( $\mathrm{t}$ hitung $>\mathrm{t}$ tabel). Dari hasi analisis statistik tersebut menunjukkan bahwa tingkat pengetahuan kelompok perlakuan yang diberikan edukasi dengan menggunakan metode CBIA menghasilkan nilai yang lebih tinggi dibandingkan kelompok kontrol yang tidak diberikan edukasi.
\end{abstract}

Kata kunci: Penatalaksanaan demam, swamedikasi, cara belajar ibu aktif

\begin{abstract}
Pharmacological therapy in fever patients is to provide Antipyretic drugs, can be done by using a doctor's prescription or by self-treatment. The condition that occurs in the community is self-medication conducted in the category of irrational treatment therapy because it is not in accordance with the condition of the patient. So, it is necessary to do education using Active Mother's Ways of Learning Method to the housewives about rational fever self-treatment. The sample in this study were 40 housewives in the Flamboyant Bawah, divided into two major groups namely the control and treatment groups. Each group was given a pretest and posttest in a questionnaire of fever management. In the treatment group, fever drug education given before posttest by used CBIA method. The results showed an increase in knowledge of housewives from before education and after education was seen from the acquisition of grades. The mean pretest value in the control group was 74.38 and the treatment group was 69.69. Statistical test results show there was no significant difference in the mean value between the control group and the treatment group. The mean posttest value in the control group was $77.8 \mathrm{I}$ and the treatment group was 87.50. There was a significant difference between the mean value of the control group and treatment group. From the results of the statistical analysis showed that the level of knowledge of the treatment group given education by used the CBIA method produced a higher value than the control group that was not given education.
\end{abstract}

Keywords: Management of fever, self-medication, the Active Mother's Ways of Learning Method

\section{PENDAHULUAN}

Pengobatan sendiri adalah penggunaan obat oleh masyarakat untuk tujuan pengobatan sakit ringan (minor illnesses), tanpa resep atau edukasi dokter (Kristina et al., 2008). Mudahnya memperoleh obat tanpa resep yang banyak dijual di pasaran akan menimbulkan kecenderungan yang semakin meningkat di kalangan masyarakat untuk melakukan pengobatan sendiri (Suryawati, 1997 dalam Kristina et al., 2008). The International Pharmaceutical Federation (FIP) mendefinisikan swamedikasi atau selfmedication sebagai penggunaan obat-obatan tanpa resep 
oleh seorang individu atas inisiatifnya sendiri (FIP, 1999). Sedangkan definisi swamedikasi menurut WHO adalah pemilihan dan penggunaan obat modern, herbal, maupun obat tradisional oleh seorang individu untuk mengatasi penyakit atau gejala penyakit (WHO, 1998).

Menurut Kartajaya (20II), fenomena pengobatan sendiri (termasuk pembelian obat tanpa resep) ini disebabkan oleh beberapa hal. Pertama, perkembangan teknologi informasi, semakin berkembangnya teknologi, masyarakat menjadi lebih mudah dalam mengakses informasi, termasuk informasi mengenai kesehatan. Alasan swamedikasi, peresepan sendiri, atau pembelian obat tanpa resep di masyarakat Indonesia, adalah karena penyakitnya dinilai ringan (46\%), harga yang lebih murah (16\%), dan obat mudah didapat (9\%). Terlihat bahwa faktor biaya dan waktu menjadi alasan yang melatarbelakangi swamedikasi.

Berdasarkan data yang didapat dari Dirjen Binfar (2008), lebih dari $60 \%$ masyarakat mempraktekkan selfmedication ini, dan lebih dari $80 \%$ di antara mereka mengandalkan obat modern. Apabila dilakukan dengan benar, maka selfmedication merupakan sumbangan yang sangat besar bagi pemerintah, terutama dalam pemeliharaan kesehatan secara nasional. Berdasarkan penelitian Supardi et al., (1999), prevalensi ibu rumah tangga yang menggunakan OB (obat bebas) atau OT (obat terbatas) dalam upaya pengobatan sendiri sebulan terakhir sebesar $74,4 \%$. Persentase terbesar responden menggunakan OB $(80,9 \%)$ dan hanya sebagian kecil menggunakan OT $(19,1 \%)$.

Ibu memiliki peranan penting sebagai penentu kesehatan dan kualitas sumber daya anggota keluarga. Hal ini dikarenakan perempuan lebih peka dan memegang peran penting dalam pengambilan keputusan mengenai kesehatan dalam keluarga termasuk dalam memilih obat yang akan digunakan ketika salah satu keluarga mengalami gangguan kesehatan (Zoraida, 2012). Banyaknya informasi mengenai iklan obat bebas dan obat bebas terbatas berpengaruh besar terhadap banyaknya masyarakat yang melakukan pengobatan sendiri (Maulana, 2009). Banyaknya obat yang dijual dipasaran memudahkan masyarakat untuk melakukan swamedikasi, tetapi pada pelaksanaan swamedikasi dapat terjadinya kesalahan pengobatan (Medication error) karena keterbatasan pengetahuan masyarakat tentang obat dan penggunaannya. Masyarakat hanya cenderung melihat merk obat tanpa mengetahui kandungannya.

Metode Cara Belajar Ibu Aktif (CBIA) merupakan metode penyampaian informasi obat dengan melibatkan subjek secara aktif yaitu mendengar, melihat, menulis, dan melakukan evaluasi tentang pengenalan jenis obat dan bahan aktif yang dikandung, serta informasi lain seperti indikasi, kontra indikasi, dan efek samping (Suryawati, 2003).
Metode CBIA ini merupakan metode pembelajaran bagi para ibu rumah tangga karena dari banyak survey telah diketahui bahwa ibu rumah tangga adalah "key person" dalam penggunaan obat di rumah. Metode CBIA telah terbukti lebih efektif dapat meningkatkan pengetahuan pengobatan sendiri $(4,9 \pm 0,3$ menjadi $8,3 \pm 0,2 ; P<0,00 \mathrm{I})$, sedangkan yang menghadiri seminar besar hanya terjadi peningkatan dari 4,5 $\pm 0,6$ menjadi 6,4 $\pm 0,3 ; P \leq 0,05$, dan pada grup kontrol hampir tidak ada peningkatan yaitu dari 4,2 $\pm 0,4$ menjadi 4,8 $\pm 0,3$.

CBIA adalah model edukasi pemberdayaan masyarakat agar lebih terampil memilih obat sehingga swamedikasi menjadi lebih efektif, aman, dan hemat biaya. Metode Cara Belajar Ibu Aktif (CBIA) adalah metode pendidikan yang bertujuan untuk menumbuhkan sikap kritis dari peserta latih sehingga timbul motivasi/keinginan untuk melakukan sesuatu, baik berupa motivasi dari luar/keluarga maupun motivasi dari dalam individu peserta latih tersebut, motivasi untuk menemukan, sehingga fasilitator hanya berfungsi sebagai motivator atau pendorong agar minat dan potensi peserta latih dapat berkembang. Tujuan CBIA adalah terbentuknya kemampuan untuk menggali sumber informasi dan meningkatkan kebiasaan berpikir secara kreatif dan kritis sehingga mampu memecahkan masalah yang didasarkan pada proses belajar mandiri (self learning) (Suryawati, 20I2)

Oleh karena itu peneliti memilih metode CBIA untuk meningkatkan pengobatan rasional terutama pada penyakit demam dengan meningkatkan pengetahuan ibu rumah tangga untuk memilih obat demam yang tepat. Demam sendiri merupakan salah satu penyakit yang banyak diderita oleh masyarakat baik dari usia anak-anak maupun usia dewasa.dan kecenderungan masyarakat lebih sering mengobati penyakit demam dengan melakukan pengobatan sendiri atau swamedikasi. Pada penelitian ini peneliti akan menggunakan ibu-ibu rumah tangga yang tinggal di daerah kawasan yang padat dengan tingkat perekonomian menengah kebawah. Hal ini dikarenakan pengobatan sendiri atau swamediaksi biasa dilakukan oleh masyarakat dengan tingkat perekonomian menengah kebawah. Karena jika masyarakat melakukan pengobatan sendiri akan menekan biaya pengobatan bila dibandingkan harus memeriksakan dirinya kepada dokter atau rumah sakit.

\section{METODOLOGI}

Rancangan penelitian yang digunakan adalah quasy experiment yang bersifat non-equivalen control group design. Dalam desain ini terdapat dua kelompok yaitu kelompok perlakuan dan kelompok kontrol. Untuk mengetahui tingkat pengetahuan, sikap dan perilaku pengobatan sendiri sebelum perlakuan diberikan pretest baik pada kelompok perlakuan maupun pada kelompok control. Selanjutnya 
kelompok perlakuan diberikan edukasi dengan metode CBIA. Untuk mengukur perubahan pengetahuan, sikap dan perilaku sesudah edukasi diberikan posttest dengan pertanyaan yang sama pada kedua kelompok. Jumlah sampel yang dilibatkan adalah sebanyak 40 orang ibu rumah tangga yang tergabung dalam kelompok arisan Langgar Nurul Iman kawasan perumahan Flamboyant Bawah Kota Palangkaraya. Desain penelitian ini digambarkan pada Tabel I.

Tabel I. Desain Penelitan

\begin{tabular}{lccc}
\hline & Pretest & Perlakuan & Posttest \\
\hline Kelompok A & ZI & & Z2 \\
Kelompok B & Z3 & $\sqrt{ }$ & Z4 \\
\hline
\end{tabular}

Keterangan:

A : Kelompok kontrol

$B$ : Kelompok eksperimen dengan perlakuan menggunakan metode CBIA

ZI: Pengukuran pertama sebelum diberi edukasi (Pretest)

Z2: Pengukuran kedua setelah edukasi (Postest) pada kelompok kontrol

Z3: Pengukuran pertama pada kelompok eksperimen

Z4: Pengukuran kedua pada kelompok eksperimen

$\checkmark$ : Perlakuan

\section{HASIL DAN PEMBAHASAN}

Pada penelitian ini yang bertindak sebagai sampel adalah ibuibu rumah tangga di Kawasan Flamboyant bawah yang tergabung dalam kelompok arisan Langgar Nurul Iman. Penelitian dilakukan pada kegiatan arisan yang dilaksanakan setiap hari Jumat pada pukul 14.00-selesai. Jumlah sampel yang dilibatkan adalah sebanyak 40 orang dan dibagi dalam dua kelompok besar yaitu kelompok kontrol dan perlakuan. Untuk melihat tingkat pengetahuan peserta sebelum penelitian maka dilakukan pretest kepada kedua kelompok dengan menjawab soal kuisioner penatalaksanaan demam. Selanjutnya dilakukanlah edukasi pengetahun terhadap kelompok perlakukan dengan menggunakan metode CBIA. Pada proses penelitian kelompok perlakukan dibagi kembali menjadi 5 kelompok besar yang terdiri 4 orang sampel yang di damping oleh 2 orang asisten peneliti yang bertindak sebagai tutor dalam hal ini mahasiswa Prodi DIII Farmasi UMP yang akan membimbing peserta dalam pelaksanaan metode CBIA. Pada proses edukasi setiap kelompok akan diberikan alat peraga yaitu berupa obat demam dalam berbagai macam bentuk sediaan obat Parasetamol seperti tablet, sirup dan drop. Selain bentuk sediaan juga diperkenalkan sediaan Parasetamol dalam bentuk bentuk generik dan patennya. Sampel penelitian akan diminta untuk menuliskan nama obat, indikasi, cara penggunaan, efek samping serta kontraindikasi yang tercantum dalam setiap kemasan obat. dengan cara ini para ibu rumah tangga akan belajar untuk memilih obat demam yang tepat sesuai dengan kondisi umur pasien baik untuk orang dewasa, anak-anak, balita dan bayi. Selain itu para peserta penelitian akan diberikan informasi mengenai cara penyimpanan obat yang demam. Setelah dilakukan edukasi pada kelompok perlakuan selanjutnya untuk mengetahui apakah ada perubahan setelah dilakukan metode CBIA maka dilakukan postest dengan menjawab kuisioner yang sama pada saat pretest. Postest juga dilakukan kepada kelompok kontrol yang bertindak sebagai pembanding.

Hasil yang didapat dari penelitian yang telah dilakukan adalah adanya peningkatan pengetahuan para ibu rumah tangga dari sebelum di lakukan edukasi dan setelah edukasi. $\mathrm{Hal}$ ini dapat dilihat dari perolehan rata-rata nilai setelah menjawab soal yang diberikan. Rerata nilai pretest pada kelompok kontrol adalah 74.38 dan kelompok perlakuan sebesar 69.69. Dan dari hasil uji statistik menunjukkan tidak ada perbedaan yang signifikan rerata nilai antara kelompok kontrol dan kelompok perlakuan ( $t$ hitung<t tabel). Sedangkan hasil analisis yang didapat rerata niali postest pada kelompok kontrol adalah 77.8I dan kelompok perlakuan sebesar 87.50. Dari hasil uji statistik didapatkan terdapat perbedaan yang signifikan antara rerata nilai antara kelompok kontrol dan kelompok perlakuan ( $\mathrm{t}$ hitung $>\mathrm{t}$ tabel). Dari hasi lanalisis statistik tersebut menunjukkan bahwa tingkat pengetahuan kelompok perlakuan yang diberikan eduaksi dengan menggunakan metode CBIA menghasilkan nilai yang lebih tinggi dibandingkan kelompok kontrol yang tidak diberikan edukasi. Hal ini menunjukkan bahwa $\mu 1>\mu 2$, secara analisis statistic dapat disimpulkan bahwa penggunaan metode CBIA dapat meningkatkan pengetahuan ibu-ibu rumah tangga dalam penatalaksanaan demam. Pada metode CBIA hal terpenting yang harus dipahami oleh peserta adalah bahwa informasi secara cepat dan tepat dapat diperoleh dari informasi yang terdapat di kemasan-kemasan obat. Dengan metode CBIA peserta dituntut untuk terlibat secara aktif dalam mencari informasi yang tersedia dengan menuliskan kembali bahan aktif beserta dosis pada lembar kerja yang telah disediakan. Selain itu sampel obat yang diberikan merupakan obat dengan nama aktif yang sama tetapi dengan berbagai macam bentuk sediaan yang berbeda serta nama dagang yang berbeda. Sehingga para peserta dapat mengetahui secara tepat bagaiman memilih obat demam yang rasional sesuai dengan kondisi pasien yang tepat. Pada metode CBIA ini peranan tutor sangat besar dalam mengarahkan dan mendorong peserta untuk mencari informasi secara lengkap. Dengan adanya metode CBIA ini para ibu-ibu rumah tangga yang memiliki peranan dalam pelaksanaan pengobatan sendiri bagi anggota keluarga dapat menyebarluaskan pengetahuan dan keterampilan memilih obat demam yang tepat baik kepada anggota keluarga maupun orang-orang terdekat.

Metode CBIA merupakan salah satu upaya yang dapat dilakukan untuk meningkatkan penggunaan obat yang rasional karena dapat memberikan informasi dan edukasi 
kepada masyarakat. Dan diperlukan partisipasi dari semua unsur baik tenaga kesehatan, akademisi dan masyarakat sendiri agar swamedikasi terutama untuk gangguan kesehatan keluarga dapat terlaksana secara rasional sehingga meningkatkan derajat kesehatan masyarakat.

\section{KESIMPULAN}

Kesimpulan yang didapat dari penelitian ini adalah dengan menggunakan metode CBIA dapat meningkatkan pengetahuan ibu rumah tangga dalam penatalaksanaan demam dengan melakukan pengobatan sendiri atau swamedikasi.

\section{UCAPAN TERIMA KASIH}

Ucapan terimakasih kepada Universitas Muhammadiyah Palangkaraya atas pemberian dana dalam skema Hibah Penelitian Kajian Perempuan dan Anak melalui Lembaga Penelitian dan Pengabdian Masyarakat.

\section{DAFTAR PUSTAKA}

Dirjen Bina Kefarmasian dan Alkes Depkes RI. 2008. Materi Pelatihan Peningkatan Pengetahuan dan Keterampilan Memilih Obat Bagi Tenaga Kesehatan. Jakarta

Kartajaya, H., 20II, Self Medication. Jakarta Selatan: PT MarkPlus Indonesia.

Kristina, S.A., Prabandari, Y.S., Sudjaswadi, R., 2008. Perilaku pengobatan sendiri yang Rasional pada masyarakat Kecamatan Depok dan Cangkringan Kabupaten Sleman. Majalah Farmasi Indonesia. 19(1):32-40.

Maulana, H. D. J. 2009. Promosi Kesehatan. Jakarta: EGC.

Suryawati, S., 2003. CBIA: Improving The Quality Of SelfMedication Through Mothers Active Learning. Essential Drugs Monitor. 032:22-23.

Suryawati Sri. 2012. Meningkatkan Keterampilan Memilih Obat Dengan Metode CBIA, Pusat Studi Farmakologi Klinik dan Kebijakan Obat UGM. Yogyakarta

Supardi, S., Aais, S., Sukasediati, N. 1999. Pola Penggunaan Obat Dan Obat Tradisional Dalam Upaya Pengobatan Sendiri Di Pedesaan. Cermin Dunia Kedokteran, 125:5-8.

WHO, 1998, The Role of The Pharmacist in Self-Care and SelfMedication. The Hague, The Netherlands

Zoraida, A. R. 2012. Peningkatan Ketrampilan Mencari Informasi Pada Kemasan dan Lembar Sisipan Obat bebas dan Bebas Terbatas dengan Metode Cara Belajar Ibu Aktif (CBIA). Yogyakarta: Fakultas Farmasi Universitas Gadjah Mada. 